\title{
Oculoauriculovertebral spectrum with radial defects
}

INSERM

\section{Source}

INSERM. (1999). Orphanet: an online rare disease and orphan drug data base.

Oculoauriculovertebral spectrum with radial defects. ORPHA:2549

Oculoauriculovertebral spectrum (OAVS) with radial defects is a rare branchial arches and limb primordia development disorder characterized by variable degrees of uni- or bilateral craniofacial malformation and radial defects that result in extremely variable phenotypic manifestations. Characteristic features include low postnatal weight, short stature, vertebral defects, hearing loss, and facial dysmorphism (incl. facial asymmetry, external, middle, and inner ear malformations, orofacial clefts, and mandibular hypoplasia). These features are invariably associated with radial defects, such as preaxial polydactyly, thumb and/or radius hypoplasia/agenesis, or triphalangeal thumb. Cardiac, pulmonary, renal, and central nervous system involvement has also been reported. 